\title{
Exploring Enablers and Barriers to Municipal Solid Waste (MSW) Management Technologies Adoption in the Kingdom of Bahrain
}

\author{
S. Y. Abbas ${ }^{1}$, K. Kirwan², D. Lu ${ }^{3}$ \\ ${ }^{1}$ Department of Natural Recourses \& Environment, Arabian Gulf University, Salmaniya, Manama, Bahrain \\ ${ }^{2}$ Sustainable Material and Manufacturing Group, WMG, University of Warwick, Coventry, UK \\ ${ }^{3}$ Supply Chain and Logistics, WMG, University of Warwick, Coventry, UK \\ Email: sumayayousif@agu.edu.bh, kerry.kirwan@warwick.ac.uk,D.Lu@warwick.ac.uk
}

How to cite this paper: Abbas, S.Y., Kirwan, K. and Lu, D. (2020) Exploring Enablers and Barriers to Municipal Solid Waste (MSW) Management Technologies Adoption in the Kingdom of Bahrain. Journal of Environmental Protection, 11, 377-398. https://doi.org/10.4236/jep.2020.115022

Received: January 14, 2020

Accepted: May 5, 2020

Published: May 8, 2020

Copyright $\odot 2020$ by author(s) and Scientific Research Publishing Inc. This work is licensed under the Creative Commons Attribution International License (CC BY 4.0).

http://creativecommons.org/licenses/by/4.0/

\begin{abstract}
Municipal Solid Waste (MSW) becomes a point of focus globally due to its harmful effects on the environment and human health if it is not managed properly. MSW was proved globally to be used as a resource, and it has a major opportunity in the realm of conversion technologies. Accordingly, this study aims to explore the enablers and barriers to six different MSW management (MSWM) technologies adopted in the Kingdom of Bahrain, in order to ensure the successful adoption of these technologies that are Anaerobic Digestion (AD), Incineration, Pyrolysis, Gasification, Composting and Refused Derived Fuel (RDF). This study provides sufficient information to the decision and policy-makers for the processes of selection and adoption of the MSWM technologies in Bahrain, using a qualitative approach "mainly semi-structured interviews" with experts and then Thematic Analysis using nvivo12 software. The results show that the main themes that enablers and barriers fall under are: political (e.g. national waste management strategy), technical (e.g. segregation at source), managerial (e.g. capacity building), social (e.g. public awareness), economic (e.g. incentives to investment) and environmental (e.g. air quality). This study concluded that in order to succeed in the MSWM technologies adoption, the resulted barriers should be overcome. Furthermore, Incineration was recommended as the best solution to manage MSW which has the least barriers and most enablers in Bahrain as per the experts.
\end{abstract}

\section{Keywords}

Municipal Solid Waste Management, Technology Adoption, Enablers, Barriers, Thematic Analysis, Kingdom of Bahrain 


\section{Introduction}

In the modern era, consumption habits of individuals resulting from the contemporary lifestyles have led to a severe problem of wastage, especially in large cities. This issue is now being addressed at the international level [1] [2]. Solid waste management is regarded as a critical challenge faced by modern societies [3] that is harmful to human health and to the environment at large. The increased economic and developmental activities of a city directly affect the production and consumption patterns, which in turn leads to an increase in waste generation.

Waste management can be regarded as a "basic human right". Ensuring the provision of proper sanitation and solid waste management, potable water, shelter, food, energy, transport, and communication forms part of an essential right for the society at large [1].

The Gulf Council Cooperation (GCC) countries ranked among the highest waste generating countries per capita worldwide [2]. The Kingdom of Bahrain forms part of the list of GCC countries. The total amount of waste generated in the GCC ranges from 90 million to 150 million metric tons annually, with the UAE being the highest generator per capita at approximately $2.2 \mathrm{~kg}$ [3]. The amount of recycled waste is around 5percent of the total, with the rest being accounted for landfills or illegal dumpsites. The amount of waste generated is expected to grow rapidly to anywhere between 1.5 and 2 times the current volume in 2021 [3]. As is the situation in most developing countries, all the GCC countries are dumping their MSW in landfills as the main and only waste management option, which has negative impacts environmentally, economically and socially. In the Kingdom of Bahrain, there is one MSW landfill called Askar Landfill, which has reached its maximum capacity recently. This critical situation makes finding sustainable alternatives to manage MSW in the country very crucial.

\section{MSW Management Options}

Generally, an effective management of solid waste includes planning, policy-making and execution, assessment, reporting, and legislation. Elements of solid waste management may include the control of waste generation, storage, collection, transfer and transport, processing (i.e. segregation), and proper disposal. Different research projects, technical studies and researches have been performed worldwide to investigate the best methods of solid waste management [4].

Moreover, waste-to-energy technologies are used to convert municipal solid waste elements, such as paper, plastics, and wood in order to generate energy by thermochemical or biochemical conversion processes. [5] demonstrated the efficacy of Waste Treatment Technologies: Pyrolysis, Gasification, Composting and anaerobic digestion in waste treatment and disposal while [6] pointed out at the MSW incineration as a very important waste management technology. The 
most common technique of waste-to-energy is combustion, which entails the burning of municipal solid waste to create steam for heating or to generate electricity. This paper aims to explore the enablers and barriers to the adoption of each of the MSWM technologies including AD, incineration, composting, RDF, gasification and pyrolysis in Bahrain, using qualitative methodology, particularly semi-structured interviews with experts. The efficacy of the data collection method has been demonstrated in several studies to explore the barriers to technology adoption in several sectors [7] [8] [9] [10] [11].

\section{Literature Review}

[12] stated that $\mathrm{WtE}$ technologies can improve waste management in the fast-growing cities of developing and emerging countries but added that its application is complex and must consider the following barriers: 1) Lower calorific value in MSW than in industrialized countries owing to the high moisture (high organic content) and mineral content in waste (e.g. ash, construction and demolition waste); 2) Substantial seasonal change in waste composition (i.e. changing consumption patterns during festival seasons, seasonal crops); 3) Limited practice of waste segregation at source; 4) Weak business and operation models; 5) Lack of knowledge on operating and maintaining WtE plants; 6) High investment and operating costs which cannot be recovered by existing waste fees and generated additional income from energy sales alone; 7) Neglecting livelihood issues for marginalized persons and informal sector workers based on the availability of recyclables in the waste; 8) Lack of monitoring and weak enforcement of environmental standards, leading to public health issues.

These barriers might be the same in Bahraini context since the lack of waste separation at source coupled with the lack of information and public awareness represented by people perception; attitude and behavior may play a key role in the successful adoption of MSWM technologies. The lack of evidence-based studies about the main enablers and barriers to waste management technologies adoption in the GCC countries has paved the way for this research paper that aims to enable researchers and decision makers in these countries to overcome the barriers and reach a successful technology adoption in future.

[4] is one of the very few researchers and experts who theoretically discussed the challenges of waste management sector in the GCC area. He argues that GCC waste management sector is currently facing multiple challenges in the form of:

Lack of clear and reliable framework by which the solid waste sector is administered from the collection, transformation to disposing or treatment phases.

The absence of effective and comprehensive legislative frameworks governing the solid waste sector and the inadequate enforcement mechanisms.

Management activities of MSW are considered public services, which are directly controlled by governmental institutions.

Inadequate human and organizational capacities and capabilities. 
The paucity of accurate and reliable background data and information on the status of solid waste.

Moreover, according to [1], it was found that waste management in Bahrain is hindered by the following factors:

1) Low level of Commitment: there is a disconnect between the high-level policy makers and the lower entities responsible for waste management (NGOs, people, industries, etc..) that hinders commitment to the implementation of a sustainable waste management policy and the provision of necessary resources.

2) Weakness in Governance: at Entity level-uncoordinated governance and conflict of interest due to regulatory, operational, duplication and overlapping of responsibilities.

3) The scarcity of data: entity managers lacking data management, effective controls and monitoring systems, tools, and resources to do the job. The data requested for this report from the entities indicated a significant lack of detail, consistency, and systems for control, monitoring and recording, and poor and inconsistent historical records.

[12] argued that high initial investment costs tend to be a major barrier to developing MSWI projects in developing countries. Attempts are being made to bring low-cost MSWI projects to the market with a basic technical standard for low-income countries; however, there is limited experience with these solutions and it remains to be seen if these plants can successfully meet the necessary technical and emissions standards in the long term.

Moreover, [12] claimed that the operation of highly complex MSWM technologies requires well developed technical and management skills. It is much more complex than the operation of a sanitary landfill. Only managers, engineers and technicians with proven capabilities and experiences should be assigned key functions. If these qualifications are not available locally, international experts must be contracted on a long-term basis and capacity building program needs to be launched. Thus, it can be concluded that the lack of the well-trained manpower represents the main barrier to incineration technology adoption.

Environmental legislation in most developing and emerging countries do not explicitly deal with the application of MSW incineration technology. This makes the entire process of impact assessment and operation licensing more complicated and time-consuming. During the unavailability of comprehensive and legally binding standards, these should first be developed and follow the application of internationally recognized standards. An example of orientation can be the European waste incineration directive (Industrial Emissions Directive). It also needs good capacity for monitoring and enforcement within public institutions [12].

\section{Methodology}

The qualitative approach was used in this study. The semi-structured interview 
used in this study included a mixture of open-ended questions which allowed the respondents to formulate their own answers. Interviews targeted 11 experts as the study focus group. The interview was oral, and main questions were designed in Microsoft Office Word 2013; they comprised general specific questions for each technology. The interview was undertaken in Arabic and/or English. The duration of most interviews was an hour and a half, but some lasted two hours and one of them lasted 30 minutes. Designed interview-mainly semi-structured interview-was used to interview the experts in the field of waste management and technology in order to explore the enablers and barriers to the adoption of MSWM technologies in Bahrain. The efficacy of the data collection method has been demonstrated in several studies to explore the barriers to technology adoption in several sectors [7] [8] [9] [10] [11]. A combination of open and closed-ended questions was used in the survey to highlight the requirements for the enablers and barriers to MSWM technologies adoption.

\subsection{The Interview Protocol}

The experts were selected based on their high level of expertise in the field of waste management, energy, technology and project management in Bahrain. The selected experts are the most recognized in the field of waste management locally and regionally who are known for their publications, academic contribution and conferences participation. The criteria for selecting the experts is that they must be experts in the field, and have good experience and knowledge about the waste management technology adoption, in order to explore the possible enablers and barriers to the technology adoption in Bahrain.

The interviewed experts were selected from different authorities, governmental and non-governmental. They included Arabian Gulf University (AGU), Ministry of Works, Municipalities and Urban Planning (MWMUP), Gulf City Cleaning Company (GCCC), Supreme Council of Environment (SCE), private contractors and international technology supplier companies' representatives, who were interviewed in their working places to ensure that they felt relaxed when answering the questions. Participants were encouraged to talk beyond the outlined topics and discuss what they thought was important.

A total of 11 interviews were carried out between April and May 2018, each of which lasted between 30 and 80 minutes. The survey consisted of 11 main questions falling into the following main categories: the most preferred technology for Bahrain from their point of view, general enablers and barriers to any new technology adoption in Bahrain, enablers and barriers to each of $\mathrm{AD}$, Incineration, Composting, Gasification, Pyrolysis and RDF adoption in Bahrain, as well as suggestions to overcome these barriers.

Face-to-face interviews were undertaken by the researcher in most instances; when this failed, which was the case with two experts, a telephone interview was carried out in the first case whereas the second one was done via email. One of the international experts requested to send him the interview questions by email 
since he is located abroad and face-to-face interview was not possible, so he answered them completely and resent them via email within three days.

The interview always began with an overview of the purpose of the research and survey in particular. Anonymity was highlighted and consent was obtained from each expert. These interviews were written by taking notes using a paper and a pen. After finishing the interview, the researcher reviewed the answers and instantly requested more clarification if any point was missed.

The collected data were analysed using the qualitative data analysis method using thematic analysis software NVivo, which is considered as one of the most commonly used methods of qualitative analysis. It is a widely used foundational method of analysis in the realm of qualitative research [13]. It analyses, interprets and reports different themes within the overarching theme of qualitative data, which allows for flexibility in the researcher's choice of theoretical framework [14]. Thematic analysis is similar to content analysis, but focuses more on the qualitative aspects [15].

The researcher became acquainted with the data by reading and re-reading the interview quotes of the participants to understand the main contents. Thereafter, the researcher generated initial codes in order to create categories to facilitate further.

The interpretation and description of findings were divided into predominant themes, followed by sub-themes or topics. The identification of these topics is based on the research objectives, related to the research background described above. Table 1 illustrates the experts' codes, date of the interview, duration and language used through the course of the interview:

Table 1. Experts codes, description, date of the interview, duration and language used.

\begin{tabular}{cccc}
\hline Expert Code & Date of the Interview & Duration & Language \\
\hline 1 & $9^{\text {th }}$ April, 2018 & $8: 00-9: 30 \mathrm{am}$ & Arabic \\
2 & $10^{\text {th }}$ April, 2018 & $8: 45-10: 00 \mathrm{am}$ & English \\
3 & $10^{\text {th }}$ April, 2018 & $12: 00-2: 00 \mathrm{pm}$ & English \\
4 & $11^{\text {th }}$ April, 2018 & $1: 30-3: 00 \mathrm{pm}$ & Arabic \\
5 & $12^{\text {th }}$ April, 2018 & $9: 00-10: 30 \mathrm{am}$ & Arabic \& English \\
6 & $12^{\text {th }}$ April, 2018 & $2: 00-3: 00 \mathrm{pm}$ & Arabic \& English \\
7 & $19^{\text {th }}$ April, 2018 & $1: 30-2: 00 \mathrm{pm}$ & English \\
8 & $23^{\text {rd }}$ April, 2018 & $12: 30-2: 00 \mathrm{pm}$ & English \\
9 & $26^{\text {th }}$ April, 2018 & $12: 30-1: 45 \mathrm{pm}$ & English \\
10 & $28^{\text {th }}$ April, 2018 & $5: 00-6: 00 \mathrm{pm}$ & Arabic \\
11 & $29^{\text {th }}$ April, 2018 & $4: 00-5: 00 \mathrm{pm}$ & English \\
\hline
\end{tabular}

As mentioned above, the data obtained from in-depth interviews were thematically analysed using QSR NVivo 12 software, which was followed by a content analysis to confirm the main themes. Nvivo 12 software was used for the purpose of data analysis following the approach of: Inserting data files in Nvivo 
12 software, Classification of respondents, Transcription of interviews, Data coding, finding themes, and developing nodes, and Exploring hierarchal chart using queries.

Similar codes were combined under one dominant theme, considering the exact meaning of themes being developed [16]. Thematic and content analysis are based on the data of in-depth interviews transcribed from the experts. The interview was conducted using protocol containing open ended questions.

\subsection{Data Coding and Identification of Themes}

Under data coding, parent nodes were formed as Enablers and Barriers, whereas child nodes are the technologies: AD, Incineration, RDF, Gasification \& Pyrolysis, and Composting. All the experts agreed that Gasification and Pyrolysis were confronted with same enablers and barriers to their adoption; thus, they were combined in one child node. Meanwhile child nodes within each technology represented the main classification of enablers and barriers of this particular technology: social, economic, technological, managerial, political and environmental.

\subsection{Identification of General Enablers and Barriers}

Six themes were developed from the theoretical framework and the questions to investigate the enablers and barriers to the MSWM technologies' adoption in the Kingdom of Bahrain. The analysis of interview transcripts revealed codes about the general enablers and barriers to six different technologies adoption in the country apart from those specified to each technology. These technologies are: Anaerobic Digestion (AD), Incineration, Gasification, Pyrolysis, Refused Derived Fuel (RDF) and Composting. These themes included Technical, Social, Political, Managerial, Economic, and Environmental.

These themes were considered and applied to each particular technology as they were mentioned by experts.

Table 2 specifies the subthemes to have emerged within each theme for the general enablers to technology adoption in Bahrain, according to the experts.

Table 2. The general enablers to technology adoption in Bahrain.

\begin{tabular}{|c|c|}
\hline Theme & Sub-theme \\
\hline Technical & $\begin{array}{l}\text { Enforce segregation at source } \\
\text { Provide supportive infrastructure } \\
\text { Deploy recycling }\end{array}$ \\
\hline Political & $\begin{array}{l}\text { Governmental support with supportive policies } \\
\text { Establish governmental Sustainable Energy Unit (SEU) } \\
\text { Centralize responsibility } \\
\text { Effective legislations }\end{array}$ \\
\hline Managerial & $\begin{array}{l}\text { Needs private sector participation } \\
\text { Needs a national waste management strategy } \\
\text { National Capacity building }\end{array}$ \\
\hline Environmental & The government supports safe technologies \\
\hline Economic & $\begin{array}{l}\text { No financial barrier in the GCC countries } \\
\text { Technology availability in the market }\end{array}$ \\
\hline
\end{tabular}


Moreover, all experts mentioned the general barriers to technology adoption in Bahrain, as delineated in Table 3.

Table 3. The general barriers to technology adoption in Bahrain.

\begin{tabular}{|c|c|}
\hline Theme & Sub-theme \\
\hline Technical & $\begin{array}{l}\text { Absence of waste segregation at source } \\
\text { Lack of land availability } \\
\text { Lack of locally-available technologies } \\
\text { Inadequate management infrastructure }\end{array}$ \\
\hline Political & $\begin{array}{l}\text { Recruiting un-qualified people in decision making positions } \\
\text { Fragmented regulations and legislations } \\
\text { Political stability } \\
\text { Lack of governmental support to initiatives from the private sector and NGOs } \\
\text { Energy is not a priority for the government }\end{array}$ \\
\hline Managerial & $\begin{array}{l}\text { Absence of a national waste management strategy } \\
\text { Absence of privatization } \\
\text { Lack of capacity building } \\
\text { Paucity of trained manpower } \\
\text { Deficiencies in waste management legislations } \\
\text { Poor planning }\end{array}$ \\
\hline Economic & $\begin{array}{l}\text { High cost } \\
\text { Lack of incentives to investment } \\
\text { Lack of investment } \\
\text { Fuel cost is subsidized } \\
\text { No structured tariff } \\
\text { Insufficient funds }\end{array}$ \\
\hline
\end{tabular}

\subsection{Resulted Themes}

\subsubsection{Theme 1: Technical}

1) Segregation at source

All experts agreed that waste segregation at source is essential to enable and succeed in any waste technology adoption in Bahrain. Expert 4 claimed that: "segregation at source is considered a key factor to succeed any technology adoption, though one challenge is the availability of space inside homes to segregate waste at source since the containers number might not be less than 3..." This indicates that most houses in Bahrain are small in size and may not be designed properly to accommodate more than one waste container, which represents a barrier to segregation at source, and in effect, an impediment to successful technology adoption. [17] observed that organic matter separation from solid waste and recyclables is essential to divert food and yard waste from landfills, and treat organic matter appropriately, which supports our results. Furthermore, Expert 4 mentioned scavengers and absence of penalties as the main barriers to segregation at source as an internal issue; he said: "scavengers are looking for aluminium cans, plastics and cardboards. The absence of penalties makes them 'steal the segregated items from any current segregation trial points to sell them since the plastic market price is affordable (30 BD/tonne)."

Therefore, it is essential to formulate deterrent penalties in order to prevent the theft of segregated wastes by scavengers and commence segregation at source 
successfully.

2) Infrastructure

Expert 5 mentioned that: "availability of supportive infrastructure is an important enabler to any technology adoption...".

3) Availability of land

Expert 4 said: "lack of land availability for the project is a barrier since the sea reclamation to provide land in Bahrain has a very high cost..." Therefore, the availability of land represents an important enabler that may specify the technology's suitability for adoption.

4) Availability of technology

Lack of locally-available technology represents an important barrier to technology adoption, according to the experts. Lack of technologies adopted in the area makes it difficult to adopt new technologies in the country, which is a barrier to any technology adoption, according to Expert 11. Expert 5 said: "The society is very low in technology management..." which reflects the immature availability of expertise with regard to new technology adoption.

\subsubsection{Theme 2: Political}

Expert 1 and 6 described political barriers as the most important player in the waste management sector in Bahrain. Expert 1 claimed that: "politics represent the main barrier in Bahrain against waste management improvement and will be for any technology adoption..." When asked about the main general barriers to technology adoption: Expert 2 said, "it is all about politics..." Therefore, the following subthemes were explored under political barrier based on the experts' interviews:

1) Lack of governmental support

As a barrier, lack of governmental support to initiatives from the private sector and Non-Governmental Organisations (NGOs) was mentioned by Expert 4 who said: "there are many initiatives from the private sector and NGOs that are not supported by the government". In addition, complex procedures required by government to approve any initiative that aims to improve waste segregation and recycling practices as well as awareness among people is a barrier as he claimed: " the complexity of the procedure in order to approve it makes it not possible...".

2) Lack of strategy, policies, regulations and legislations

All experts concurred that the absence of a national waste management strategy represents a main barrier to improvement and will definitely adversely affect MSWM technology adoption in the country. Expert 4 said: "all technologies need supportive policies to work properly, beside the governmental support...". Expert 2 claimed that Bahrain must plan an Integrated Waste Management System to start any further waste management technology in the future. This is a reflection of the urgent need for a clear strategy, plan, or system that can formulate and coordinate waste management sector in the country.

Expert 3 described the existing regulations as fragmented, which represent another barrier to technology adoption within the country, as he claimed: "the 
fragmented regulations and legislations here in Bahrain, makes the government to concentrate on hazardous waste management and general environmental issues and neglect the MSW management...". In addition, Expert 9 said: “there are no regulations for tariff for renewable energy projects in Bahrain, and in general the lack of effective regulations is an important obstacle to waste management technologies adoption...".

Moreover, Expert 11 thought that the focus by the government must be on reducing, reusing and recycling initiatives: "Bahrain requires a waste management sustainable development agenda regarding minimization of generated waste, reuse and recycling as a main priority." He added: "poor planning and lack of waste management legislation are barriers in addition to the absence of strategic waste management plans...”.

As a positive initiative from the government, which might be considered an enabler according to Expert 9, "the government has recently established the new Sustainable Energy Unit (SEU) which belongs to the Ministry of Electricity and Water Affairs (EWA), and it may improve the regulations in this regard...".

Expert 2 believed that "current legislations and regulations support any practice that is safe and feasible and possible based on its nature and assessment for Bahraini context".

3) Political stability

Expert 3 mentioned that political stability as a key player that could have an adverse impact in waste management; therefore, it represented a barrier against technology adoption. He claimed: "Political stability affects the investment...". Since Bahrain has been undergoing political instability since 2011, experts thought that it may affect investment in the country, including investing in WM projects.

4) Centralization of responsibility

All experts agreed that the efforts of waste management in Bahrain must be centralized under one umbrella. In this regard, Expert 6 said, "the absence of interlink between the whole system parties represents a barrier since it is a nexus, so efforts must be integrated and complementary...". Furthermore, Expert 10 said, "there are several bodies responsible for waste management in the country, from government, private sector, NGOs ... etc. who are responsible for each part of waste. This leads to weakness of waste management process in the country." Expert 3 agreed and said: "it is important to create a Waste Management Directorate which is a kind of centralization of the waste management responsibilities...".

5) Recruitment policy

Government's lack of confidence in national capabilities was frequently confirmed by many experts. Expert 6 claimed that, "the government depends on foreign experts who miss the perception of the nature of our countries and ignore the national expertise in many situations." Furthermore, Expert 1 said: "the decision makers are listening and recruiting people representatives in the municipality councils who are not well qualified and their knowledge is very limited to specific areas but still they gave themselves the right to say wrong information 
and they are listened to by the government. The government is recruiting the wrong people and making decisions based on this, it's all about political considerations..." whereas Expert 4 claimed "the main barrier in Bahrain is that there are many unqualified persons in the decision-making positions, which makes an obstacle against improvement...”.

\subsubsection{Theme 3: Managerial}

1) Shortage of capacity building

Many experts believed that the shortage of capacity building was an important barrier to the adoption of waste management technologies in Bahrain. Expert 11 claimed that "shortage of skilled manpower and deficiencies in technical and operational decision-making are important barriers to technology adoption...". Expert 8 agreed and said "well trained manpower is required including expertise to operate them...". In addition, Expert 6 believed that there is no capacity building in Bahrain, which represents a barrier to any technology adoption in the future.

2) Privatization

Many experts believed that the waste management sector in Bahrain must be managed by the private sector and not directly by the government, in order to create more opportunities for improvement and open competitiveness and create innovative solutions in the waste management sector, create job opportunities to lower unemployment and improve quality of life in Bahrain. Furthermore, privatization may lead to the lower cost of disposal to the government, as Expert 1 said: "to privatize the final disposal will minimize the cost...". Expert 2 agreed: "private sector is better to manage the waste sector...".

3) Availability of supportive information

It is important to provide information in support of the application of technologies by the government. Experts agreed that the lack of related data and information about waste generation rate, volume, distribution per area, sufficient and full statistics on waste, etc... are important in order to have a full view of the waste generation in the country. In this regard, Expert 11 said: "scarcity of reliable data and accurate information on the solid waste status in Bahrain is another barrier to technology adoption...".

\subsubsection{Theme 4: Environmental}

Environmental Impacts

Environmental barrier was mentioned directly only by Expert 2 who said, "The government supports any technology that doesn't have environmental impacts and harmful effects on human health and environment.", while other experts mentioned the environment as an important enabler indirectly within their answers on the other questions of the interview which is an indication of the high importance of this theme for MSWM technology adoption in the country.

\subsubsection{Theme 5: Economic}

1) Fuel cost subsidy and oil dependency 
Another techno-economic barrier was clarified by Expert 8 who claimed, "Bahrain is an oil country, which means that there is no need for a new energy resource practically, and the fuel cost is subsidized by the government which means the availability of fuel in low cost. This represents a barrier against the waste-to-energy projects initiatives in the country, because getting energy is not a priority for the government...".

He added: "These projects might be attractive for the government by changing the point of attraction, when the priority from the project was to reduce the waste volume, get rid of odours, and have a safe disposal then these technologies might be more attractive...".

Expert 9 added that the government subsidizes fuel cost and electricity, which is why they are available at a low cost, thus representing a barrier to the waste-to-energy technologies deployment. Therefore, the motivation for the government to adopt waste management technologies is not to have a new source of energy, since the fossil fuel is available in quantities that can secure the next generations, especially after the recent discovery of the largest oil well in Bahrain history, although the government may find it more attractive to use motivation such as enhancing the scene and getting rid of environmental impacts accompanying waste dumping.

2) Lack of incentives to investment

Many experts agreed that the lack of incentives to investment in waste management technologies was considered to be a barrier to their adoption. According to Expert 8 "the lack of the incentives to the investment in these projects represents another barrier, so these projects never get green light...".

Expert 2 said in this regard, "incentives are needed to attract investment in this sector in Bahrain since the lack of incentives to attract private investment is a barrier to improve waste sector and adopt new technologies in Bahrain...".

Furthermore, Expert 3 added, "Lack of investment represent a major barrier to technology adoption in Bahrain. It needs to encourage investment in waste recycling and waste management projects...".

Meanwhile Expert 9 believed that "there are no incentives to the green technologies including the renewable energy projects in Bahrain, and they are not economically desirable. In addition to the lack of structured tariff with low tariff proposals for government and no incentives...".

Moreover, Expert 10 opined, "the budget designated for the waste management is very low, this will lower the investment in this sector and makes it not attractive to investors...”.

3) Economic feasibility

Undoubtedly, the waste management technology's economic feasibility project assumes significance. Almost all experts mentioned that the high capital and operations/maintenance cost of a technology represents a major barrier to its adoption, especially if the benefits are unable to recover the cost; therefore, the project will not be economically feasible. Expert 9 claimed that economic aspect is the most important barrier in the country: "all technologies need feasibil- 
ity study and all goes back to the economy...". Expert 10 added: "these projects are not economically feasible, and not cost effective...". Meanwhile Expert 8 believed that "the waste management technologies are not economically feasible nor attractive...". Finally, expert 1 claimed that: "the waste management is costly to the government...".

4) Lack of market of end products

According to the aforementioned experts, it is very important for the end products to have a market. The lack of the market of the technology end products represents a barrier to technology adoption. Expert 11 said: "insufficient funds and insufficient demand for recycled products in the local market are important barriers to adoption...". Analogously, Expert 10 said, "there is no market for the end products of these technologies in Bahrain..." which makes it difficult to sell the end products locally and depend on international demand.

\subsubsection{Theme 6: Social}

1) Public awareness

Public awareness represents a key enabler to any waste management technology adoption in Bahrain as mentioned by experts. [17] argued that the lack of knowledge about management of waste in general represents major barriers to waste management. Expert 2 illustrated the role of education at an early stage in improving public awareness, which will contribute in preparing the floor for technology acceptance, he claimed: "public awareness must start at very early stage in life by improving children school curriculum to raise public awareness in order to prepare the ground to transform the community to be smart enough to accept and cooperate with regard of any technology adoption in the future". In addition, Expert 4 stressed upon the importance of smart purchasing habits in lowering waste generation that reflects a high awareness toward waste management. He said: "raising public awareness for source segregation at first is an important issue. In addition to awareness of smart purchasing, that helps in decreasing waste generation. We can't ignore the importance of communicating with people and understand their needs to be listened to...".

Expert 7 agreed and mentioned the role of education in raising public awareness; he claimed that: "increasing public awareness is a priority to start with in order to have a good waste management strategy because the power to make a change in the society starts with the education, people must be aware enough...". Expert 8 said: "public awareness is an important enabler in order to prepare the society for advance technologies."

2) Culture

Besides the importance of public awareness as a key enabler, as agreed by all experts, Expert 3 focused on cultural barrier as a main barrier against any waste management technology adoption in Bahrain. He argued that "cultural barrier is the main barrier to technology adoption in Bahrain..." since background, customs, traditions and even religious reasons may prevent them from accepting some reusing and recycling practices as essential practices to succeed any tech- 
nology adoption in the country. [17] stated that the public culture plays an important role in the success of any management practice.

3) Public attitude and acceptance

Public acceptance and attitude are the reflection of public awareness in the society. If a society is aware enough, acceptance of technology will be easy and the public will cooperate; consequently, their attitude and behaviour will be positive to succeed in the technology adoption. Expert 5 mentioned that: "sometime the technology is feasible but it is not socially accepted so it cannot be adopted successfully...”.

\section{Results: Enablers and Barriers to Each Technology}

\subsection{Identification of Enablers and Barriers to AD Adoption}

In addition to the general enablers and barriers to technology adoption in Bahrain, experts were asked about the enablers and barriers to anaerobic digestion (AD) technology adoption in Bahrain. The subthemes have emerged within each theme for enablers to AD technology adoption in Bahrain were two: Emissions are low, and it is safer and cleaner technology to environment compared to thermochemical conversion technologies.

Notably, the only AD enabler theme mentioned directly by experts was that of the environmental theme. The other themes were not mentioned as enablers, but as barriers. Since there is a need to identify barriers and overcome them to enable a technology, the focus will be on the barriers, as was evident during the in-depth interviews with experts. Accordingly, all experts mentioned barriers to $\mathrm{AD}$ technology adoption in the country, as delineated in Table 4.

Table 4. The barriers to AD technology adoption in Bahrain.

\begin{tabular}{cl}
\hline \multicolumn{1}{c}{ Theme } & \multicolumn{1}{c}{ Sub-theme } \\
\hline Political & $\begin{array}{l}\text { Lack of governmental support to complicated projects } \\
\text { Lack of governmental policies and strategy }\end{array}$ \\
Managerial & $\begin{array}{l}\text { Needs labour to segregate } \\
\text { Need highly skilled and trained manpower }\end{array}$ \\
Environmental & $\begin{array}{l}\text { Environmental impacts risk } \\
\text { Negatively affects air quality }\end{array}$ \\
& $\begin{array}{l}\text { Expensive with high cost } \\
\text { Economically unfeasible } \\
\text { End product has no market in Bahrain } \\
\text { Economic }\end{array}$ \\
& $\begin{array}{l}\text { Needs incentives } \\
\text { Not economically attractive }\end{array}$
\end{tabular}

\subsection{Identification of Enablers and Barriers to Incineration Adoption}

Similarly, experts were asked "What are the enablers and barriers to incineration technology adoption in Bahrain?' Various responses were answered as listed for enablers and barriers, respectively. Table 5 specifies the subthemes that emerged 
within each theme from experts for the enablers to incineration technology adoption in Bahrain, according to the experts.

Table 5. The enablers to incineration technology adoption in Bahrain.

\begin{tabular}{|c|c|}
\hline Theme & Sub-theme \\
\hline Technical & $\begin{array}{l}\text { Reduce volume to save the limited land } \\
\text { Produce energy to generate electricity } \\
\text { Availability of technology } \\
\text { Proven in the GCC area } \\
\text { Simple, easy and not complicated } \\
\text { The resulting ash can be reused }\end{array}$ \\
\hline Political & Governmental support to investors exists \\
\hline Managerial & $\begin{array}{l}\text { Do not need special or highly skilled manpower } \\
\text { Few workers are needed }\end{array}$ \\
\hline Environmental & Safe to human and environment (using state-of-the-art technology) \\
\hline Economic & Financial support does exist \\
\hline
\end{tabular}

In addition to these enablers, all experts spoke about the barriers against incineration adoption in Bahrain, mentioned in Table 6.

Table 6. The barriers to incineration technology adoption in Bahrain.

\begin{tabular}{|c|c|}
\hline Theme & Sub-theme \\
\hline \multirow{6}{*}{ Technical } & High moisture content \\
\hline & Land for solar drying might be limited \\
\hline & Lack of land of safe distance (limited land) \\
\hline & Absence of segregation at source (mixed waste) \\
\hline & Low efficiency \\
\hline & Needs to have the most state-of-the-art technologies \\
\hline \multirow{5}{*}{ Political } & Politics represent a main barrier \\
\hline & Unqualified persons are recruited in decision making positions \\
\hline & Policy making \\
\hline & Lack of integrated waste management strategy \\
\hline & Needs strong governmental support to invest \\
\hline Managerial & Needs highly qualified and skilled manpower \\
\hline \multirow{6}{*}{ Environmental } & Environmental negative impacts \\
\hline & Dioxin and furans emissions cause serious health problems \\
\hline & Needs air collecting model \\
\hline & Problem of fly and bottom ash disposal \\
\hline & Need to clean up gases \\
\hline & Needs continuous monitoring \\
\hline \multirow{9}{*}{ Economic } & Energy is available in low cost and subsidized \\
\hline & Providing a suitable location is very expensive (sea reclamation) \\
\hline & Segregation needs additional cost \\
\hline & High cost for low benefit \\
\hline & It needs finance \\
\hline & The electricity price is subsidized \\
\hline & Not economically feasible for Bahrain \\
\hline & Small budget specified for the waste management in Bahrain \\
\hline & High operation cost, high initial cost \\
\hline
\end{tabular}




\subsection{Identification of Enablers and Barriers to Gasification and Pyrolysis Adoption}

Experts were asked "What are the enablers and barriers to gasification and pyrolysis technologies adoption in Bahrain?' On this count, all experts agreed that these technologies are not suitable for Bahrain for many reasons, and there are no enablers available to these technologies' adoption, as was concluded from their overall responses. Barriers have been listed in Table 7, which specifies the subthemes emerging within each theme from the experts for barriers to gasification as well as pyrolysis adoption in Bahrain, according to the experts.

Table 7. The barriers to gasification and pyrolysis technologies adoption in Bahrain.

\begin{tabular}{|c|c|}
\hline Theme & Sub-theme \\
\hline Technical & $\begin{array}{l}\text { Not efficient } \\
\text { Not commonly used worldwide } \\
\text { Complicated } \\
\text { Not yet tested in the gulf region } \\
\text { Not suitable for mixed waste (no segregation) }\end{array}$ \\
\hline Political & $\begin{array}{l}\text { Absence of national strategy for waste management } \\
\text { Needs to privatize waste management sector to enable them }\end{array}$ \\
\hline Managerial & $\begin{array}{l}\text { Needs very special training programs } \\
\text { Needs very high skilled manpower } \\
\text { Limited technical experience }\end{array}$ \\
\hline Economic & $\begin{array}{l}\text { High cost, expensive, not feasible } \\
\text { No market for the end product } \\
\text { Needs financing instruction to developers } \\
\text { Fuel cost subsidy } \\
\text { No incentives } \\
\text { Not economically attractive with high risk of failure }\end{array}$ \\
\hline
\end{tabular}

\subsection{Identification of Enablers and Barriers to RDF Adoption}

Experts were asked: "What are the enablers and barriers to RDF technology adoption in Bahrain?' All experts unanimously agreed that this technology is not suitable for Bahrain for a number of reasons. Barriers are listed in Table 8, which specifies the subthemes emerging within each theme from the experts in terms of barriers to RDF adoption in Bahrain.

Table 8. The barriers to RDF technology adoption in Bahrain.

\begin{tabular}{cl}
\hline Theme & \multicolumn{1}{c}{ Sub-theme } \\
\hline & Lack of segregation (mixed waste) \\
Very advanced and complicated & Commonly used in cement plants only \\
Technical & Need infrastructure \\
& Not commonly used in the region \\
Economic & No market for the end product \\
\hline
\end{tabular}




\subsection{Identification of Enablers and Barriers to Composting Adoption}

Experts were asked about the enablers and barriers to composting technology adoption in Bahrain. Most of them agreed with this option due to its simplicity, availability and cost effectiveness. Table 9 highlighted the subthemes emerging within each theme for the enablers to composting technology adoption in Bahrain according to experts.

Table 9. The enablers to composting adoption in Bahrain.

\begin{tabular}{cl}
\hline Theme & \\
\hline Technical & $\begin{array}{l}\text { Easy technology } \\
\text { Commonly used in the region and worldwide } \\
\text { Simple, not complicated } \\
\text { No need for complex equipment } \\
\text { Does not need energy to operate }\end{array}$ \\
Social & $\begin{array}{l}\text { Well recognized by people } \\
\text { Ready public acceptance }\end{array}$ \\
Political & $\begin{array}{l}\text { Accepted by the government } \\
\text { Environmental }\end{array}$ \\
& No harmful environmental impacts \\
& $\begin{array}{l}\text { Viable in small scale } \\
\text { Low initial start-up and operation costs } \\
\text { Marketable end product, can be used locally } \\
\text { Cheapest option }\end{array}$ \\
\hline
\end{tabular}

Meanwhile the subthemes emerging within each theme for barriers to composting technology adoption in Bahrain, as per experts, are listed in Table 10.

Table 10. The barriers to composting adoption in Bahrain.

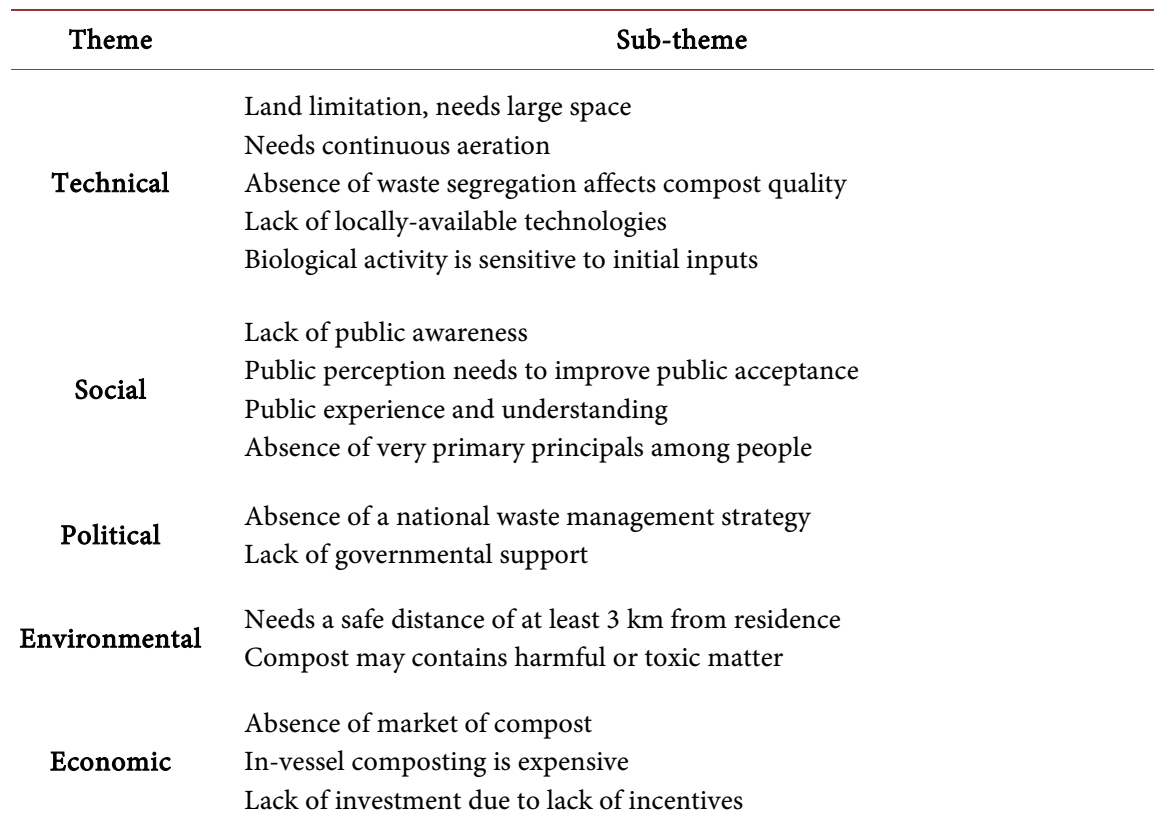




\section{Discussion}

[4] is one of the very few researchers and experts who theoretically discussed the challenges of waste management sector in the GCC area. Our findings agreed with [4] in that GCC waste management sector including Bahrain is currently facing multiple challenges. Therefore, this study was conducted and explored the enablers and barriers to MSWM technologies adoption in Bahrain for the first time using a qualitative approach. In order to compare the enablers as well as barriers to the adoption of all technologies in the country, the barriers against MSWM technologies adoption in Bahrain exceeds the enablers to them. This suggests that in order to enable the adoption, all barriers mentioned must be overcome and to that end, it is the responsibility of the government to enable the improvement of the waste management sector in Bahrain, which should begin with deployment of a national waste management strategy that encompasses a plan to raise public awareness encouraging the reduction, reuse and recycling of principal, as a key enabler to succeed in any technology adoption or good practices across the country, starting from reforming education and school curriculum at early stage, to establish a central authority in order to take responsibility of the waste management in the country.

In order to delineate the most frequent 10 words in the themes and subthemes representing the enablers and barriers of overall technology adoption in Bahrain, Cluster Analysis was used. Notably, the only valuable most frequent words are "public" and "awareness" which reflects the importance of the public awareness to enable any technology adoption in the country according to the experts, who all specified it as a main barrier to MSWM technologies adoption in Bahrain.

In this study, enablers and barriers to AD technology adoption in Bahrain were explored. It was concluded that barriers against $\mathrm{AD}$ adoption in Bahrain surpass enablers, which indicates that in order to enable its adoption, all of the above barriers must be overcome. This requires many efforts on the part of the government to improve the situation and enable technology adoption. In addition to that some parameters e.g. carbon to nitrogen ratio $(\mathrm{C}: \mathrm{N})$ and $(\mathrm{pH})$ may need to be adjusted in order to meet the optimal range to an $\mathrm{AD}$ operation. Another main barriers to AD adoption are economic: investment and high cost barriers: Installation of AD systems is capital intensive, Technological and Managerial barriers: no private sector participation, Informational access for $\mathrm{AD}$ technologies is difficult, Convenient availability of other sources of energy reduces incentives to invest in alternative and capital-intensive energy sources like biogas. In addition, the lack of local capacity to conduct operation and maintenance services for $\mathrm{AD}$, with no specific provisions or training. [18] added that the lack of governmental programs, and limited private sector support to address the financial and technical barriers discussed above, make potential private sector financing wary of focusing investment in AD. Moreover, they claimed that the lack of knowledge and experience with the biological treatment technology prevents investment in these projects. 
Enablers and barriers to incineration technology adoption in Bahrain were explored. It was concluded that barriers against incineration adoption in Bahrain exceed enablers which indicates that in order to pave the way for adoption, all of the above barriers must be overcome, which needs plenty of concerted efforts by the government to improve the situation and enable technology adoption. [19] stated the barriers to waste incineration adoption are Environment and health issues (dioxins and furans, heavy metals, $\mathrm{CO}_{2}, \mathrm{NOx}$ and $\mathrm{SOx}$ emissions and global warming), Economic issues (the cost of incineration, commercial competition and Fairness), Social issues (the public image of the incineration and the fear of toxic emissions, social pressure may create difficulties to set up infrastructure). [19] added that however, locally, state-of-the-art facilities have gained public acceptance. Technological issues are also mentioned as the trend towards more pre-treatment of the waste with separation at source may lead to lower the calorific value, thus in Bahrain, in the absence of the source-segregation of waste, it guarantees the high calorific value. And finally he stated that incineration has Management issues.

Barriers to gasification and pyrolysis adoptions in Bahrain were explored. It was concluded that barriers are dominant which indicates that all of the above barriers must be overcome. [20] agreed with our results in that high costs for technical development, repair and maintenance make it unprofitable. Moreover, [20] claimed that high moisture content dramatically reduces process energy efficiency, and varying composition and moisture content of the waste presents challenges to maintaining stable operation, which is the case with Muharraq MSW. Financial barrier leads many gasification projects to fail due to non-viability. Furthermore, [20] argued that gasification has already acquired a negative reputation in the public mind which represents another barrier to its adoption.

Barriers against RDF adoption in Bahrain were explored. Experts mentioned technical and economic barriers in order to describe the barriers to RDF adoption, and all of them concurred that co-processing for RDF is not a recommended technology for Bahrain. [12] argued that characteristics of waste, its suitability for co-processing, and the type of industry where it is applied are important enablers to RDF adoption. It needs a Cement plant with knowledge and experts for plant operation. Moreover, it needs a segregated high calorific fraction of MSW as a feedstock.

Enablers and barriers to composting adoptions in Bahrain were explored. All themes were mentioned by experts except managerial under both enablers and barriers to adoption; some experts agreed that composting is a good option to managing degradable portion of MSW in Bahrain albeit on a small-scale, while others thought that it is not suitable due to the reasons mentioned above. Moreover, the lack of woody materials, the lack of regulations for composting, and financial and time investments, make it difficult for composting to be profitable in the short term. Furthermore, the lack of experience and knowledge, besides the quality of compost all represent barriers to composting adoption in Bahrain. 


\section{Tree Map Analysis}

Tree Map Analysis shows the significance of each scheme of the study. As per the study, Incineration technology has its most critical barriers against its adoption, that is, Environmental, Political, and Technical barriers were identified by the experts as the most dominant ranging from most to least, respectively. Whereas Gasification and Pyrolysis were mostly driven by economic, technical and political barriers. Composting has mostly political and technical barriers, whereas RDF has mostly political and economic barriers.

Similarly, most dominant enablers to technology adoption which were talked about by experts were determined using the Tree Map Analysis. Importantly, only composting, $\mathrm{AD}$ and incineration currently had enablers in Bahrain according to experts, whereas RDF, gasification and pyrolysis do not have those enablers.

\section{Conclusions and Recommendations}

Incineration is the most preferred option, with reforming policies, generating a national strategy for waste management and improving public awareness. It was highly recommended that the priority is for preparing the ground using simple options and gradually goes to more complicated options, in addition to improving public awareness, with planning a sustainable national waste management strategy, which is strongly recommended. Moreover, in order to enable AD and composting, segregation policy is needed to start with. Furthermore, Bahrain needs to start with simple technologies to manage its waste. However, the priority is to reduce waste volume to save land and improve public awareness as well as to extend the landfill life span using innovative solutions, which may create jobs and conserve environment. It is highly recommended to focus on reducing, reuse and recycle principle, as the best way to manage waste in Bahrain. In addition, source segregation must be applied; as a starting point.

In conclusion, incineration was recommended as the best solution to manage MSW in Bahrain by four experts, despite the possible harmful environmental impact; the highly efficient state-of-the-art incineration technology with a highly controlled emission monitoring system is recommended to ensure avoiding these impacts. This technology is available and well recognized globally, and leads to the reduction in waste volume with electricity generation. Therefore, to enable incineration, a suitable and safe location must be provided, which is difficult in a small country like Bahrain. However, community living next to the site of a planned incinerator is engaged with, and their interests are considered from the very beginning. Besides, the poor profit-making ability and the negative environmental impact are main barriers hampering incineration technology adoption. Therefore, skilled staff can be hired and retained to enable incineration. In addition, reforming policymaking and recruitment policy are important for enabling incineration adoption in Bahrain, according to the experts in this study. 


\section{Conflicts of Interest}

The authors declare no conflicts of interest regarding the publication of this paper.

\section{References}

[1] UNEP (2017) United Nations Environment Assembly of the United Nations Environment Programme.

https://wedocs.unep.org/bitstream/handle/20.500.11822/25384/Quarterly\%20Repor t\%20to\%20the\%20CPR.pdf? sequence=54\&isAllowed $=\mathrm{y}$

[2] Al-Ansari, M.S. (2012) Improving Solid Waste Management in Gulf Co-Operation Council States: Developing Integrated Plans to Achieve Reduction in Greenhouse Gases. Modern Applied Science, 6, 60-68. https://doi.org/10.5539/mas.v6n2p60

[3] Eco-Waste (2018) GCC Waste to Energy Report towards a Zero-Waste Society. https://www.ecowaste.ae/_media/GCC-Waste-to-Energy-2018.pdf

[4] Zafar, S. (2016) Overview of Composting Methods. Ecomena. https://www.ecomena.org/composting-methods

[5] ElQuliti, S. (2016) Techno-Economical Feasibility Study of Waste-to-Energy Using Pyrolysis Technology for Jeddah Municipal Solid Waste. International Journal on Power Engineering and Energy, 7, 622-635.

[6] Williams, P.T. (2005) Waste Treatment and Disposal. John Wiley \& Sons, Hoboken. https://doi.org/10.1002/0470012668

[7] Atkin, D., Chaudhry, A., Chaudry, S., Khanelwal, A. and Verhoogen, E. (2017) Organizational Barriers to Technology Adoption Evidence from Soccer-Ball Producers in Pakistan. The Quarterly Journal of Economics, 132, 1101-1164. https://doi.org/10.1093/qje/qjx010

[8] Al-Senaidi, S., Lin, L. and Poirot, J. (2009) Barriers to Adopting Technology for Teaching and Learning in Oman. Computer and Education, 53, 575-590. https://doi.org/10.1016/j.compedu.2009.03.015

[9] Jesson, J., Pocock, R. and Stone, I. (2014) Barriers to Recycling: A Review of Evidence since 2008. The Waste \& Resources Action Programme: Banbury.

[10] Luken, R. and Rompy, F. (2008) Drivers for and Barriers to Environmentally Sound Technology Adoption by Manufacturing Plants in Nine Developing Countries. Journal of Cleaner Production, 16, S67-S77. https://doi.org/10.1016/j.jclepro.2007.10.006

[11] McNiff, K. (2016) Thematic Analysis of Interview Data: 6 Ways NVivo Can Help. http://www.qsrinternational.com/nvivo/nvivo-community/blog/thematic-analysis-i nterview-data-nvivo

[12] Mutz, D., Hengevoss, D., Hugi, C.M. and Gross, T. (2017) Waste-to-Energy Options in Municipal Solid Waste Management. A Guide for Decision Makers in Developing and Emerging Countries. Eschborn.

[13] Buetow, S. (2010) Thematic Analysis and Its Reconceptualization as "Saliency Analysis”. Journal of Health Services Research \& Policy, 15, 123-125. https://doi.org/10.1258/jhsrp.2009.009081

[14] Braun, V. and Clarke, V. (2006) Using Thematic Analysis in Psychology. Qualitative Research in Psychology, 3, 77-101. https://doi.org/10.1191/1478088706qp063oa

[15] Hevner, A. and Chatterjee, S. (2010) Design Research in Information Systems: Theory and Practice. Springer, Berlin. https://doi.org/10.1007/978-1-4419-5653-8 
[16] Bauer, M.W. and Gaskell, G. (2000) Qualitative Researching with Text, Image and Sound: A Practical Handbook for Social Research. Sage, New York. https://doi.org/10.4135/9781849209731

[17] Metson, G.S. and Bennett, E.M. (2015) Phosphorus Cycling in Montreal's Food and Urban Agriculture Systems. PLoS ONE, 10, e0120726.

https://doi.org/10.1371/journal.pone.0120726

[18] TetraTech Inc. through Eastern Research Group (2010) Barriers and Constraints to Implementation of Anaerobic Digestion System in Swine Farms in the Philippines. U.S. Environmental Protection Agency, Global Methane Initiative, Washington DC.

[19] Bontoux, L. (1999) The Incineration of Waste in Europe: Issues and Perspectives. A Report Prepared by IPTS for the Committee for Environment, Public Health and Consumer Protection of the European Parliament.

http://citeseerx.ist.psu.edu/viewdoc/download?doi=10.1.1.732.1931\&rep=rep1\&type $=\mathrm{pdf}$

[20] GAIA (2017) Waste Gasification \& Pyrolysis: High Risk, Low Yield Processes for Waste Management a Technology Risk Analysis.

http://www.no-burn.org/wpcontent/uploads/Waste-Gasification-and-Pyrolysis-hig h-risk-low-yield-processes-march2017.pdf 